\title{
Electrocardiogram in Haïssaguerre Syndrome (Early Repolarization)
}

\author{
Eletrocardiograma na Síndrome de Haïssaguerre (Repolarização Precoce) \\ Raphael Chiarini 1,2, Carlos Eduardo Duarte ${ }^{1,2, *}$, João Durval Ramalho Trigueiro Mendes Junior ${ }^{1,2}$, \\ J.Tarcísio Medeiros de Vasconcelos ${ }^{1,2}$, Silas dos Santos Galvão Filho ${ }^{1,2}$
}

ORCID IDs

Chiarini R (D) https://orcid.org/0000-0001-8619-8393

Duarte CE (D) https://orcid.org/0000-0001-6671-0820

Mendes Junior JDRT (D) https://orcid.org/0000-0002-9484-0013

Vasconcelos JTM (D) https://orcid.org/0000-0002-5152-2648

Galvão Filho SS (DD https://orcid.org/0000-0001-5236-164X

\begin{abstract}
Introduction: Early repolarization pattern (ERP) has traditionally been related as a benign variant of electrocardiography (ECG). However, since 2008, when two studies were published for Haïssaguerre et al. and Rosso et al., with evidence of a higher prevalence of ERP in people with primary or idiopathic ventricular fibrillation (VF), this paradigm has been challenged. Objective: To conduct a thorough review of early repolarization and current state of the art regarding risk stratification in these patients. Methods: Literature review on the subject evaluating the works published in high impact journals. Conclusion: The correlation of risk factors and the real value of the various methods currently available as possible risk stratifiers is still controversial. Advances in genetics and molecular biology may in the future help in understanding the pathophysiology and better risk stratification in this population. In this context, the standardization of the definition and classification of early repolarization is imperative, as it will serve as a substrate for future studies and researches in the area.
\end{abstract}

KEYWORDS: Ventricular fibrillation; Haïssaguerre syndrome, Electrocardiography; Sudden death risk; Early repolarization.

\section{RESUMO}

Introdução: O padrão de repolarização precoce (RP) tem sido tradicionalmente relacionado como uma variante benigna do eletrocardiograma (ECG). No entanto, desde 2008, quando dois estudos foram publicados por Haïssaguerre et al. e Rosso et al., com evidências de maior prevalência de RP em pessoas acometidas por fibrilação ventricular (FV) primária ou idiopática, esse paradigma tem sido contestado. Objetivo: Realizar uma profunda revisão acerca da RP e atual estado da arte acerca da estratificação de risco nesses pacientes. Métodos: Revisão da literatura acerca do tema avaliando os trabalhos publicados em revistas de alto impacto e a experiência dos especialistas sobre o assunto. Conclusão: A correlação de fatores de risco e o real valor dos vários métodos atualmente disponíveis como possíveis estratificadores de risco ainda são controversos. Avanços nas áreas da genética e biologia molecular podem futuramente auxiliar no entendimento da fisiopatologia e melhor estratificação de risco nessa população. Neste contexto, a padronização da definição e classificação da repolarização precoce mostra-se imperativa, uma vez que servirá de substrato para futuros estudos e pesquisas na área.

PALAVRAS-CHAVE: Fibrilação ventricular; Síndrome de Haïssaguerre; Eletrocardiografia; Risco de morte súbita; Repolarização precoce.

1.Beneficência Portuguesa de São Paulo, Eletrofisiologia e Estimulação Cardíaca artificial - São Paulo (SP) - Brazil. 2.Centro Avançado de Ritmologia e Eletrofisiologia, Eletrofisiologia e Estimulação Cardíaca Artificial - São Paulo (SP) - Brazil. *Correspondence author: carlosduarte@ritmologiacare.com.br Received: 08 Nov 2019 | Accepted: 19 Nov 2019 Section Editor: J. Tarcísio Medeiros de Vasconcelos 


\section{HISTORY}

The presence of a pattern of early repolarization pattern (ER) in the form of notching or slurring of the terminal part of the QRS complex on electrocardiogram (ECG) was first described in 1936 by Shipley and Hallaran ${ }^{1}$. However, the J point deflection that occurs at the junction of the QRS with the ST segment (also known as the Osborn wave or J wave) was first described by Tomaszewski in $1938^{2}$. For a long time, there was a consolidated concept that the presence of ER in the ECG was not associated with any adversity. This concept was reconsolidated by Klatsky et al. ${ }^{3}$ in 2003, in a study involving 73,088 patients submitted to the voluntary health examination, including ECG, in Oakland, California, between 1983 and 1985. The authors concluded that the prevalence of ER in their cohort was $0.9 \%(670 / 73,088)$, that patients with ER were less likely to experience arrhythmias, and that the overall rate of hospitalization and outpatient visits were not higher than in the control population.

However, in the 2000s, clinical reports, mainly from Japan, demonstrated the presence of ER as the only finding in survivors from sudden cardiac death by idiopathic ventricular fibrillation (VF), suggesting a potential nonbenign nature of ER. More definitive clinical evidence on these observations came in 2007 and 2008 with Haïssaguerre et al. ${ }^{4}$ e Rosso et al. ${ }^{5}$, respectively, in which the high prevalence of ER was associated with patients with idiopathic VF. Haïssaguerre et al. ${ }^{4}$ showed the presence of ER in 31\% (64/206) of idiopathic VF cases versus $5 \%$ in the control group $(P<0.001)$. Rosso et al. ${ }^{5}$, in 2008 , based on data stored in implantable cardioverter-defibrillator, observed that 64 idiopathic VF survivors with ER experienced higher VF recurrences than the 142 survivors of $\mathrm{VF}$ without ER (41\% vs. 23\%, $\mathrm{P}=0.008)$. In 2015, Macfarlane et al. ${ }^{6}$ published a consensus to standardize the diagnosis of ER. In 2016, in a survey of the American Heart Association, it was estimated that the incidence of ER in the general population could be higher than $10 \%$. Given the evidence brought by recent publications, the American College of Cardiology (ACC), the American Heart Association (AHA) and the Heart Rhythm Society (HRS) jointly published a guide for management of patients with ventricular arrhythmias and prevention of sudden cardiac death including patients with early repolarization syndrome, bringing back the importance of the topic.

\section{DEFINITION}

The definition of early repolarization (ER) has been changing since its first description by Tomaszewski in $1938^{2}$. A consensus was recently published in 2015 by Macfarlane et al. ${ }^{6}$ aiming to standardize the criteria for the correct definition and characterization of this pattern. It was then defined that the ER can be presented in the form of two distinct patterns, namely the notching pattern and the clogging pattern. The ER is present when all of the following criteria are met:

1. Presence of notching or slurring (delay) in the descending branch of the $\mathrm{R}$ wave. If a notching is present, it must be located above the baseline, as well as the beginning of the slurring at the end of the $\mathrm{R}$ wave.

2. The peak of the end-QRS notching (Jp point) or the beginning of the end-QRS slurring (Jp point) should be $\geq 0.1 \mathrm{mV}$ on two or more related leads in the 12-lead electrocardiogram, except from $\mathrm{V} 1$ to $\mathrm{V} 3$.

3. The duration of the QRS must be $<120 \mathrm{~ms}$.

Therefore, according to this consensus, the isolated elevation of the ST segment, in the absence of notching or slurring in the $\mathrm{R}$-wave descending branch, should not be described as early repolarization.

As a form of standardization for future studies and the application of definition criteria, it is recommended the correct measurement of the following intervals based on each pattern of ER presentation (Fig. 1) ${ }^{6}$ :

- Notching pattern:

1. The amplitude of the Ji point at the beginning of the notching;

2. The amplitude of the Jp point at the peak of the notching;

3. The amplitude of the Jt point at the end of the notching;

4. The duration D1 from Ji to Jp;

5. The duration D2 from Ji to Jt.

- Slurring pattern:

The amplitude of the Jp point at the beginning of the slurring; 

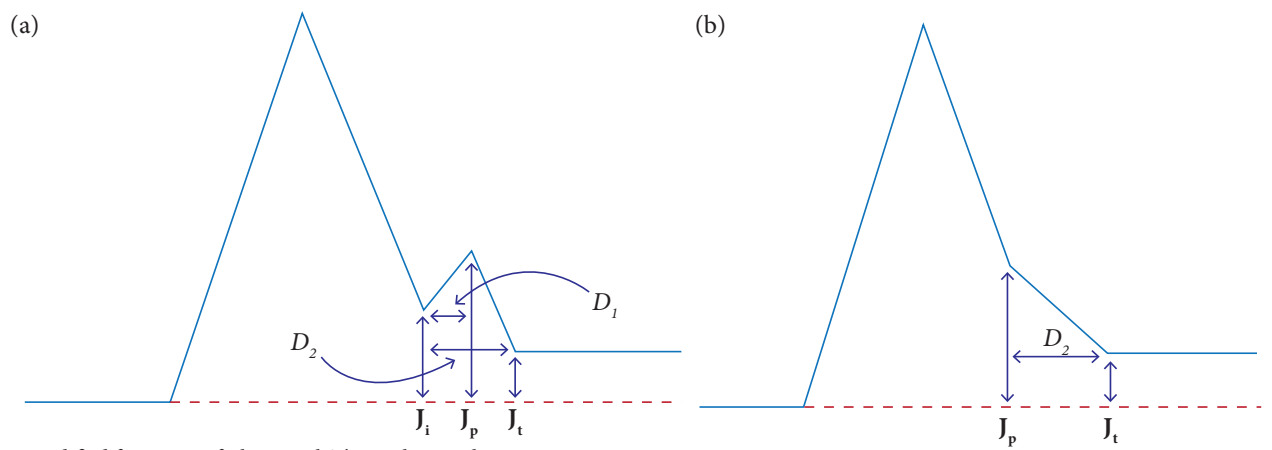

Modified from : Macfarlane et al. The Early Repolarization Pattern: a consensus paper. 2015; 66:470-7

(a): Initial J amplitude $\left(\mathrm{J}_{\mathrm{i}}\right)$, J peak $\left(\mathrm{J}_{\mathrm{p}}\right)$, and $\mathrm{J}$ end $\left(\mathrm{J}_{\mathrm{t}}\right)$ and durations $\mathrm{D}_{1}$ and $\mathrm{D}_{2}$ in notching pattern.

(b): $\mathrm{J}_{\mathrm{p}}$ and $\mathrm{J}_{\mathrm{t}}$, and the duration $\mathrm{D}_{2}$ in slurring pattern, as stated in the text.

Figure 1. Notching and slurring patterns.

The amplitude of the Jt point at the end of the slurring;

The D2 duration of Jp to Jt.

Other recommendations regarding measurement:

- QRS duration:

It is recommended that the QRS duration be measured in those derivations that do not have notching or slurring so that the QRS duration is not overestimated.

- Existence of end-QRS slurring in QRS complexes:

The confirmation of the existence of the end-QRS slurring can be done through the presence of an angle higher than 10 degrees between a line drawn at the end of the QRS and the beginning of the slurring (Fig. 2) ${ }^{6}$ :

Note: Slurring can be determined by drawing the line at the end of the QRS and another at the slurring point if the angle between them is greater than 10 degrees.

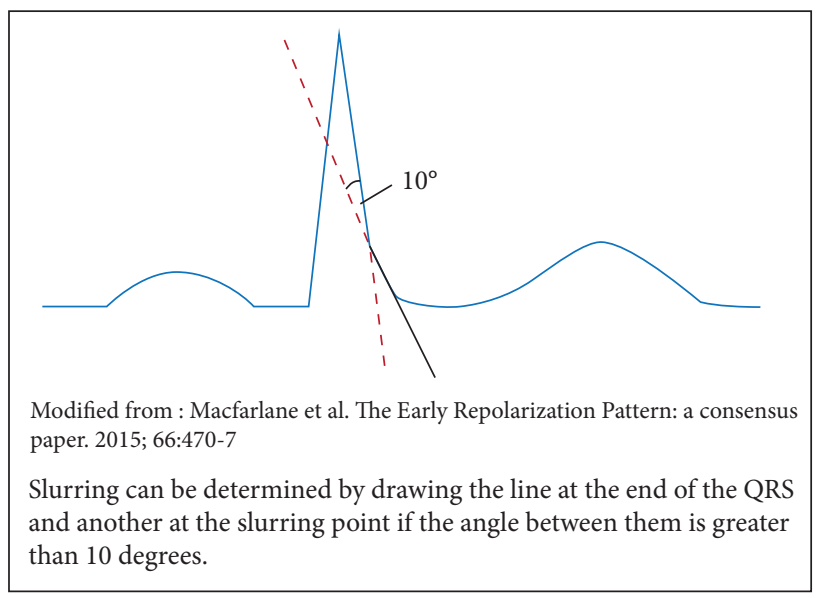

Figure 2. Existence of slurring.

\section{ETIOPATHOGENESIS}

Since its description, many theories have been proposed about the understanding of the precursor mechanism of the ER phenotype and how it may predispose some patients with this alteration to an increased risk of arrhythmias. The understanding of etiopathogenesis requires the identification and detailed characterization of the electrophysiological substrate in the structurally intact heart of patients with early repolarization syndrome.

The clinical phenotype of ER syndrome is defined based on changes in the morphology of conventional body surface ECG, according to criteria already described in this study. These changes in the final QRS component with late characteristics may reflect either late activation or early repolarization; these two possibilities cannot be differentiated in comparison to conventional surface ECG.

The name early repolarization syndrome was given based on a hypothesis, not on a confirmed underlying mechanism. Therefore, the first question to be answered in order to understand this phenomenon is: are ECG abnormalities in patients with $\mathrm{ER}$ due to delayed activation in ventricular regions or due to early regional ventricular repolarization? Seeking an answer to this question, Zhang et al. ${ }^{7}$ published in 2017 a study in which patients with ER were submitted to noninvasive electrocardiographic imaging (ECGI). The ECG potentials were acquired simultaneously by 256 electrodes using a multichannel data acquisition, and then the patients were submitted to thoracic computed tomography with ECG to obtain the epicardial geometry and positions of the thoracic electrodes (Fig. 3) ${ }^{8}$ : 
The noninvasive ECGI revealed the presence of an abnormal electrophysiological substrate in patients with $\mathrm{ER}$, characterized by a shortened duration of the action potential, accentuated repolarization gradients, and regional distribution of J-wave electrograms in the epicardium. Accentuated repolarization gradients provide substrate

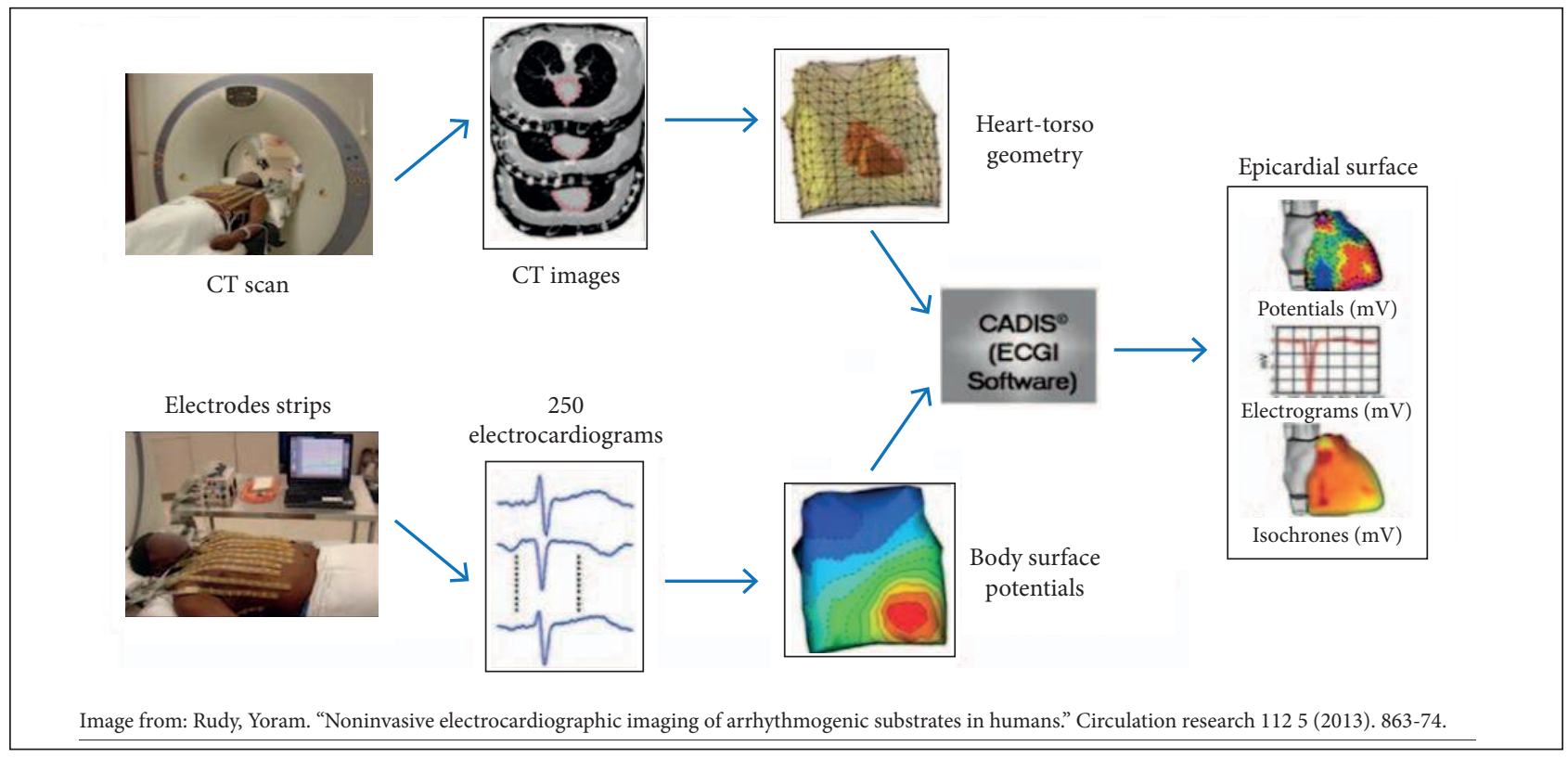

Figure 3. ECG with 250 electrodes and construction of the epicardial image using tomography.

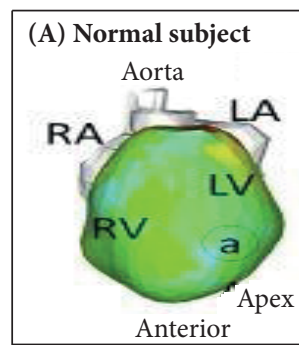

(C) Patient ER-14

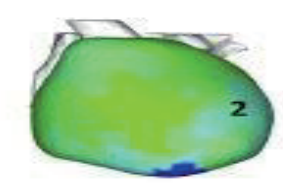

Anterior
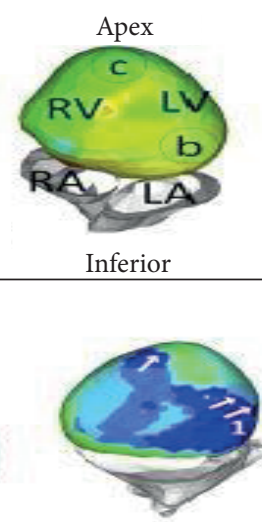

Inferior
(B) Patient ER-11

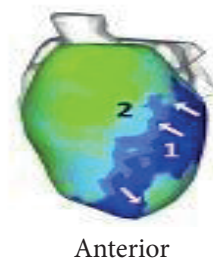

(D) Patient ER-20

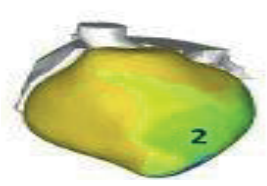

Anterior
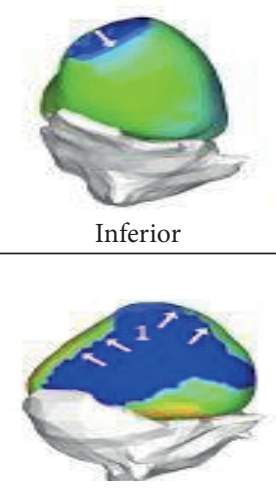

Inferior

(E) Electrograms
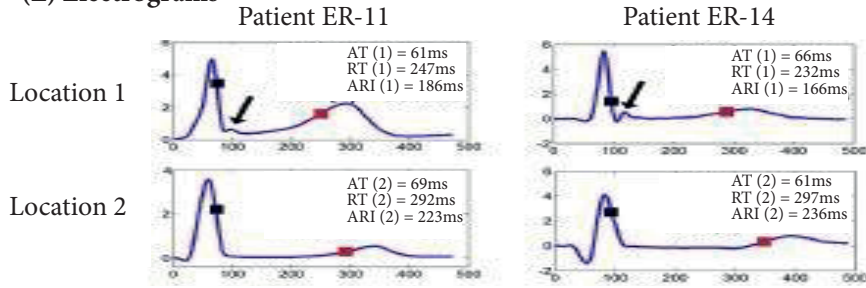

Normal subject
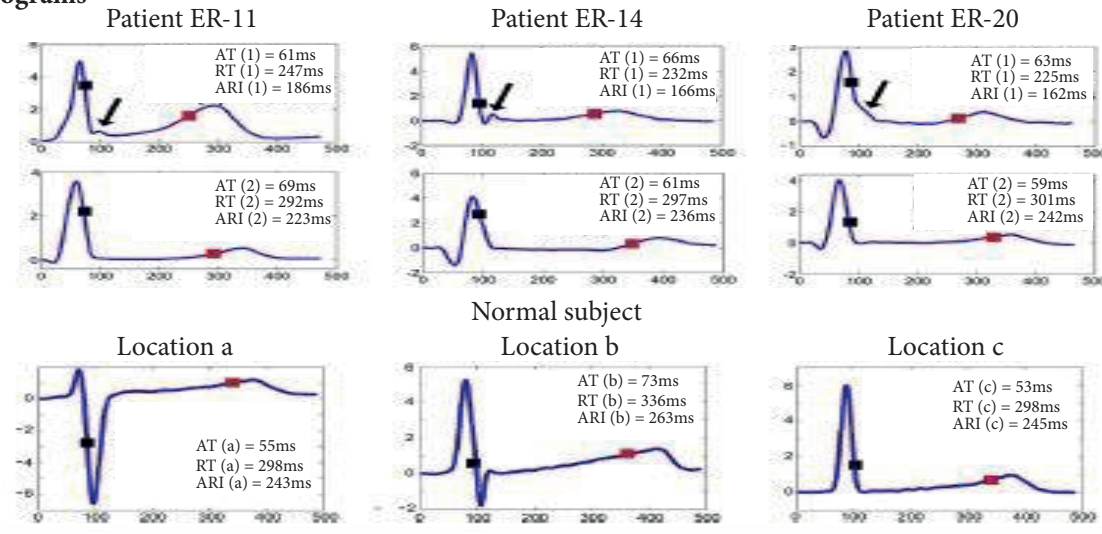

Modified from:

Zhang et al. The substrate of Early Repolarization

Syndrome. JACC: Clinical Electrophysiology. Mar 2017.

Figure 4. Sinus rhythm activation-recovery interval map. 
susceptible to the development of asymmetrical conduction and reentrant arrhythmias. It was possible to correlate the sites of origin of ventricular extrasystoles in regions with the presence of $\mathrm{J}$ wave and accentuated repolarization gradients mapped during sinus rhythm (Fig. 4$)^{7}$.

\section{CLINICAL AND ELECTROCARDIOGRAPHIC CLASSIFICATION}

The manifestation of early repolarization can be classified concerning its clinical manifestation or electrocardiographic presentation.

Clinically, we can divide it into two presentations:

- Early repolarization syndrome (Haïssaguerre syndrome): $\mathrm{J}$-spot elevation $\geq 0.1 \mathrm{mV}$ in two related leads, inferior or lateral, with notching or slurring of QRS, in patients with a report of recovered sudden death, documented VF or polymorphic ventricular tachycardia, or with family pattern (genetic mutation).

- Early repolarization pattern: the presence of electrocardiographic alteration: J-point elevation $\geq 0.1 \mathrm{mV}$ in two related leads, inferior or lateral, with a QRS-end notching (J-wave) or slurring.

Regarding the electrocardiographic presentation, in addition to the patterns already described for notching and slurring, the ER should be classified with the ST segment (as can be seen in Figs. 5 and 6):

- Early repolarization with ascending ST segment;

- Early repolarization with horizontal ST segment;

- Early repolarization with descending ST segment ${ }^{6}$.

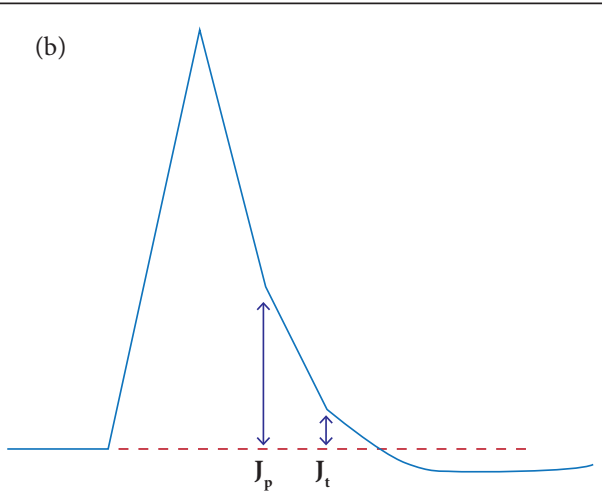

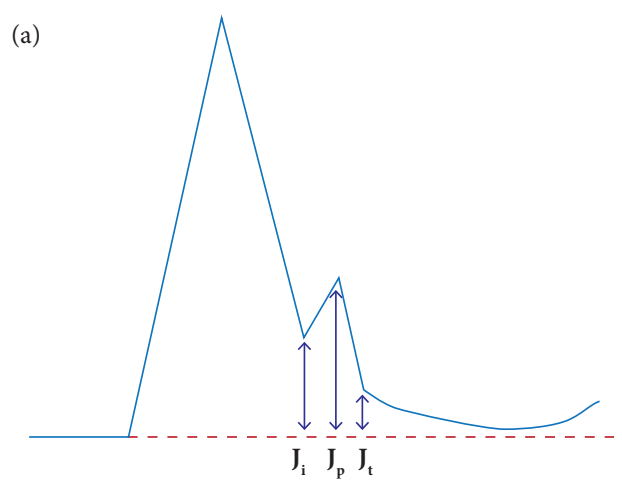

Modified from : Macfarlane et al. The Early Repolarization Pattern: a consensus paper. 2015; 66:470-7

(a): Ji, Jp, and Jt measurements in the notching pattern with a horizontal ST segment.

(b): Jp and Jt measurements in slurring pattern with descending ST segment.

Figure 5. Notching measurements in the descending pattern and slurring measurements in the ST descending pattern.

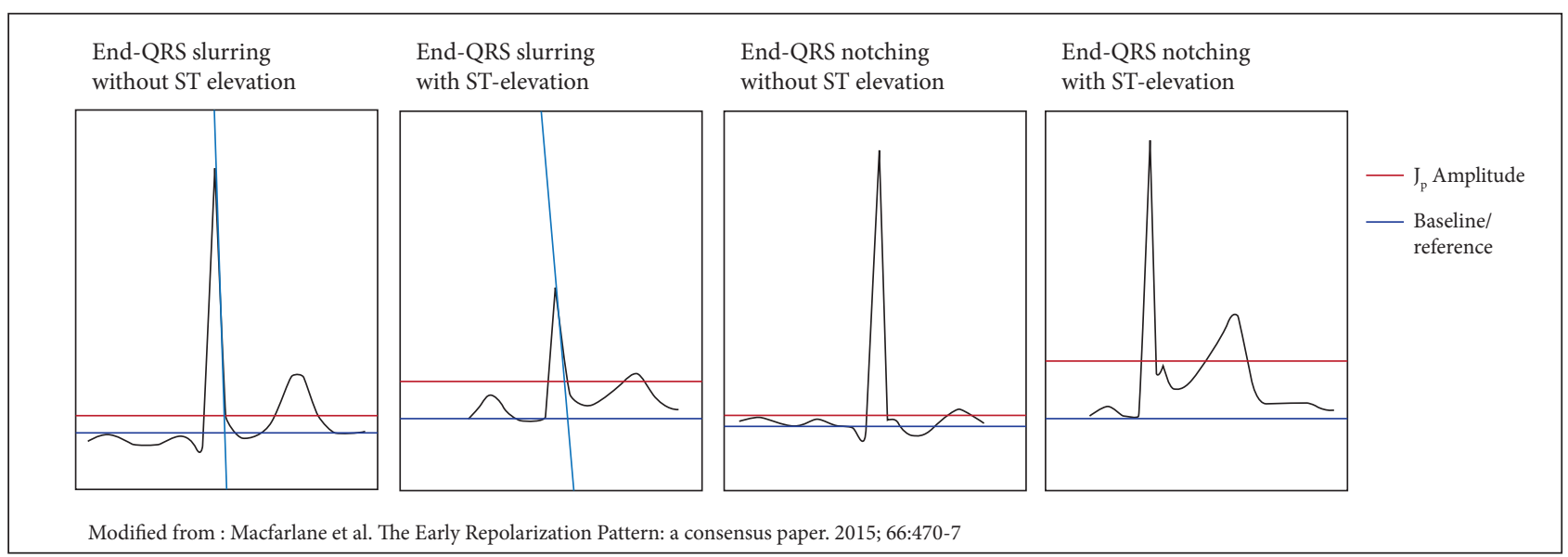

Figure 6. Jp-point evaluation in QRS with and without ST-segment elevation. 


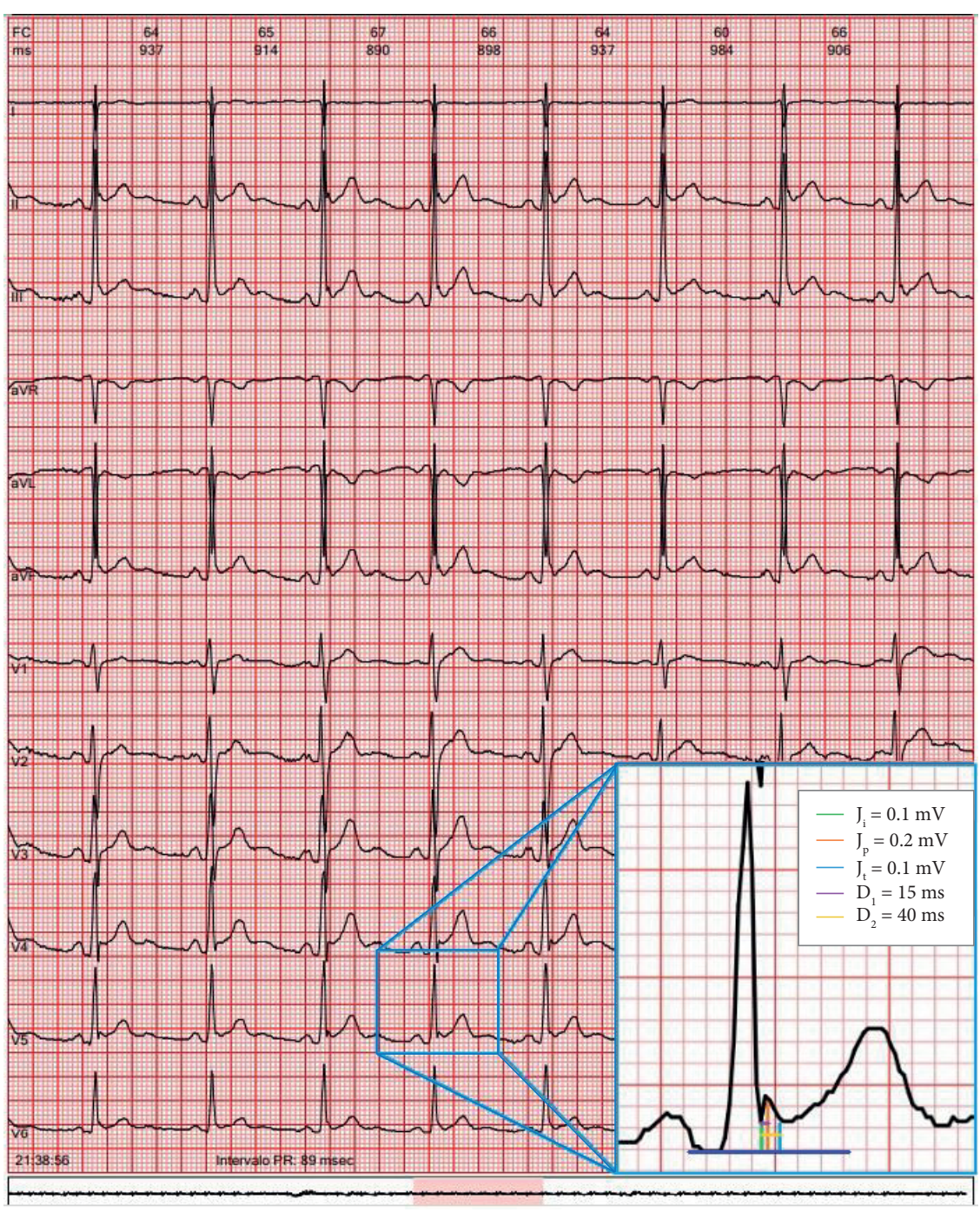

Figure 7. ECG and VCG examples.

\section{CLINICAL RELEVANCE}

The pattern of early repolarization has traditionally been related as a benign variant of the ECG and has been considered as a useful health marker, for being present in young people and athletes. It is estimated that the prevalence of ER in the general population is between 1 and 13\%, with the higher prevalence reported among young patients. However, since 2008, when two studies were published by Haïssaguerre et al. ${ }^{9}$ and Rosso et al. ${ }^{5}$, with evidence of the higher prevalence of ER in people with primary or idiopathic ventricular fibrillation (VF), this paradigm has been contested. Rosso et al. ${ }^{5}$ demonstrated a higher prevalence of J-point elevation in the group of survivors of sudden death in comparison with the group of young and adult athletes of the control group 5 (Fig. 8); it also correlated the leads in which the ER evidence presented a higher relation with idiopathic VF episodes (Fig. 9).
In 2015, Mahida et al. ${ }^{10}$ published a study in which 81 patients with an ER pattern on the ECG who experienced an episode of sudden death aborted by VF, and then all had implantable cardioverter-defibrillator. These patients were selected from an international record of idiopathic VF containing 367 patients. These patients were submitted to standard protocols of electrophysiological study (EPS) for induction of $\mathrm{VF}$ and then by serial interrogation of the implantable cardioverter-defibrillator. In this group, it was possible to induce VF during EPS in only 18 of the 81 (22\%) patients; 6 of the 18 (33\%) patients presented new episodes of VF recorded by the implantable cardioverter-defibrillator during follow-up. Regarding the group of patients in whom it was not possible to induce VF during the EPS, 21 of the 63 (33\%) experienced new episodes of VF documented by the implantable cardioverter-defibrillator throughout the follow-up, demonstrating that the current pacing protocols 


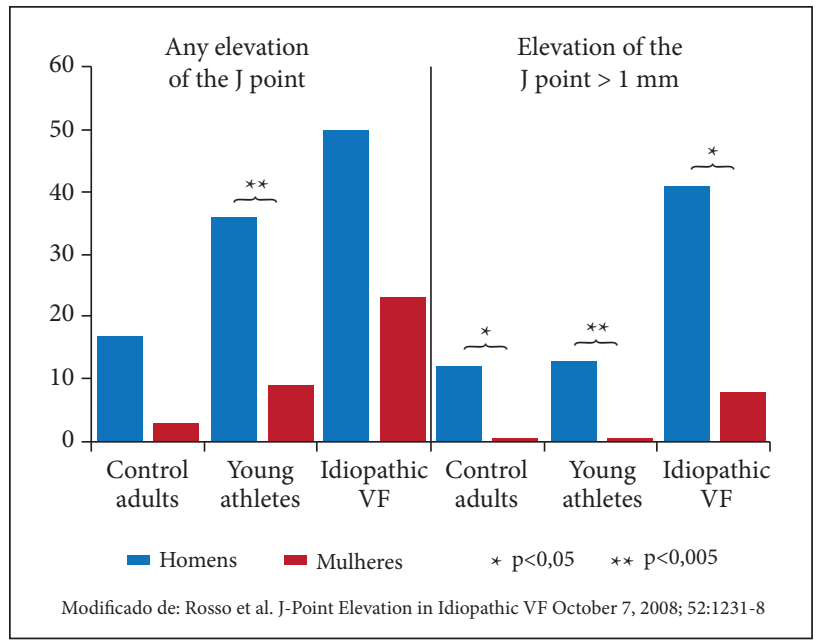

Figure 8. Influence of the type of the incidence of J-point elevation in different groups of patients.

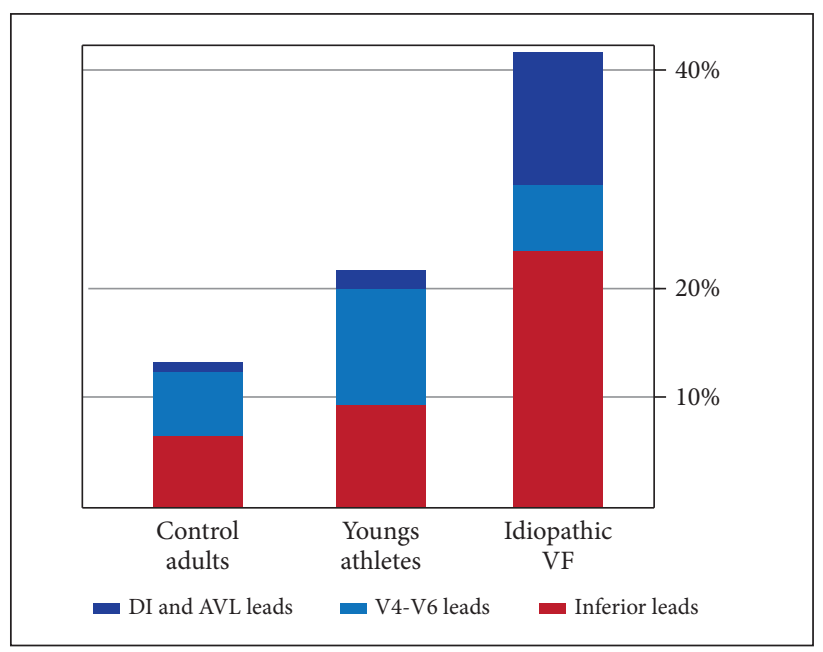

Figure 9. Distribution of the J-wave prevalence in the different groups of patients.

during the electrophysiological study did not increase the risk stratification of ventricular fibrillation in patients with Haïssaguerre syndrome. In contrast, in a retrospective analysis, Mahida et al. ${ }^{10}$ proposed correlated risk factors in this study population as possible predictors of risk for sudden death (Fig. 10) ${ }^{10}$ :

In 2017, the American College of Cardiology (ACC), the American Heart Association (AHA) and the Heart Rhythm Society (HRS), based on a review of recent publications, jointly published a guide for management of patients with ventricular arrhythmias and prevention of sudden cardiac death ${ }^{11}$ including patients with early repolarization syndrome (Table 1 ).

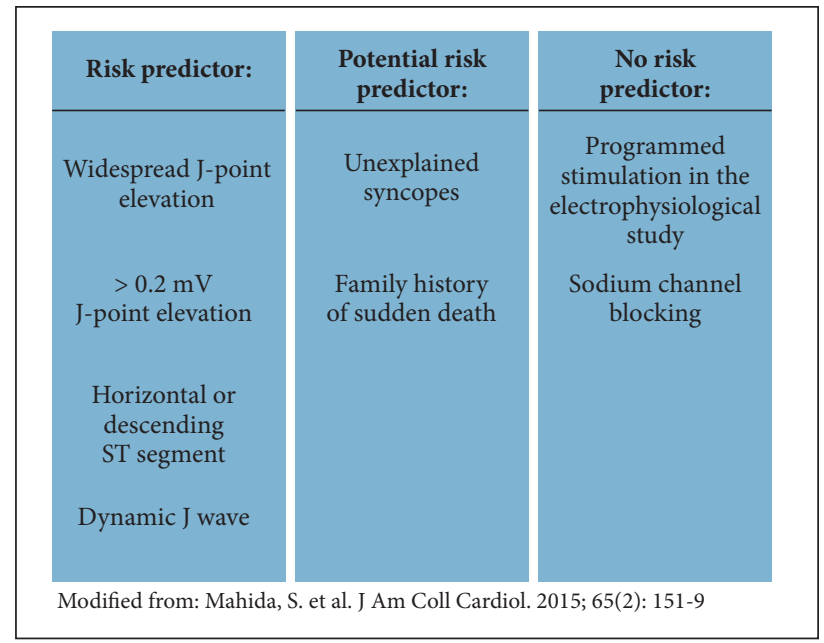

Figure 10. Records in the present study in the context of risk factors previously identified for sudden death in patients with early repolarization syndrome.

Table 1. Recommendations for early repolarization syndrome.

\begin{tabular}{ccc}
\hline RC & LE & \multicolumn{1}{c}{ Recomendation } \\
\hline I & B-NR & $\begin{array}{c}\text { 1. In asymptomatic patients with an ECG ER } \\
\text { pattern, observation without any treatment is } \\
\text { recommended. }\end{array}$ \\
\hline I & B-NR & $\begin{array}{l}\text { 2. In patients with an ECG ER pattern and } \\
\text { cardiac arrest or sustained ventricular } \\
\text { tachycardia, cardioverter-defibrillator } \\
\text { implantation is recommended. }\end{array}$ \\
\hline & B-NR & $\begin{array}{l}\text { 3. In patients with an ECG PR pattern, genetic } \\
\text { testing is not recommended. }\end{array}$ \\
\hline
\end{tabular}

RC: Recommendation Class; LE: Level of evidence ${ }^{12}$.

\section{CONCLUSION}

Although several studies have demonstrated the relation between the presence of early repolarization and an increased incidence of sudden cardiac death, the correlation of risk factors and the real value of the various methods currently available as possible risk stratifiers are still controversial. Future advances in genetics and molecular biology may help in understanding the pathophysiology and better risk stratification in this population. In this context, the definition and classification of early repolarization must be standardized since it will serve as a basis for future studies and research in the area.

\section{AUTHORS' CONTRIBUTION}

All the authors contributed equally to this paper. 


\section{REFERENCES}

1. Shipley RA, Hallaran WR. The four lead electrocardiogram in 200 normal men and women. Am Heart J. 1936;11(3):32545. https://doi.org/10.1016/S0002-8703(36)90417-9

2. Tomaszewski W. Changement electrocardiographiques observes chez un homme mort de froid. Arch Mal Coeur Vaiss. 1938;31:525-528.

3. Klatsky AL, Oehm R, Cooper RA, Udaltsova N, Armstrong MA. The early repolarization normal variant electrocardiogram: correlates and consequences. Am J Med. 2003;115(3):171-7. https://doi.org/10.1016/s0002-9343(03)00355-3

4. Haïssaguerre M, Sacher F, Derval N, Jesel L, Deisenhofer I, Roy L, et al. Early repolarization in the inferolateral leads: A new syndrome associated with sudden cardiac death. I Interv Card Electrophysiol. 2007;18(3):281. https://doi.org/10.1007/s10840-007-9136-7

5. Rosso R, Kogan E, Belhassen B, Rozovski U, Scheinman MM, Zeltser $D$, et al. J-point elevation in survivors of primary ventricular fibrillation and matched control subjects: incidence and clinical significance. J Am Coll Cardiol. 2008;52(15):12318. https://doi.org/10.1016/j.jacc.2008.07.010

6. Macfarlane PW, Antzelevitch C, Haïssaguerre M, Huikuri HV, Potse M, Rosso R, et al. The early repolarization pattern: a consensus paper. J Am Coll Cardiol. 2015;66(4):470-7. https://doi.org/10.1016/j. jacc.2015.05.033

7. Zhang J, Hocini M, Strom M, Cuculich PS, Cooper DH, Sacher F, et al. The Electrophysiological Substrate of Early Repolarization Syndrome - Noninvasive Mapping in Patients. JACC: Clinical Electrophysiology. 2017;3(8):894-904. https://doi.org/10.1016/j. jacep.2016.12.017

8. Yoram R. Noninvasive electrocardiographic imagin of arrhythmogenic substrates in humans. Circ Res. 2013;125(5):96374. https://doi.org/10.1161/CIRCRESAHA.112.279315

9. Haïssaguerre M, Derval N, Sacher F, Jesel L, Deisenhofer I, Roy L, et al. Sudden cardiac arrest associated with early repolarization. N Engl J Med. 2008;358(19):2016-23. https://doi.org/10.1056/ NEJMoa071968

10. Mahida S, Derval N, Sacher F, Leenhardt A, Deisenhofer I, Babuty $D$, et al. Role of electrophysiological studies in predicting risk of ventricular arrhythmia in early repolarization syndrome. J Am Coll Cardiol. 2015;65(2):151-9. https://doi.org/10.1016/j. jacc.2014.10.043

11. Haïssaguerre M, Sacher F, Nogami A, Komiya N, Bernard A, Probst $\checkmark$, et al. Characteristics of recurrent ventricular fibrillation associated with inferolateral early repolarization role of drug therapy. J Am Coll Cardiol. 2009;53(7):612-9. https://doi.org/10.1016/j. jacc.2008.10.044

12. Al-Khatib SM, Stevenson WG, Ackerman MJ, Bryant WJ, Callans DJ, Curtis AB, et al. 2017 AHAACC/HRS guideline for management of patients with ventricular arrhythmias and the prevention of sudden cardiac death, Heart Rhythm. 2017;15(10):e73-189. https://doi. org/10.1016/j.hrthm.2017.10.036
13. TikkanenJT,Anttonen O,Junttila MJ,Aro AL, KerolaT, Rissanen HA, et al. Long-term outcome associated with early repolarization on electrocardiography. N Engl J Med. 2009;361(26):2529-37. https://doi.org/10.1056/NEJMoa0907589

14. Mehta MC, Jain AC. Early repolarization on scalar electrocardiogram. Am J Med Sci. 1995;309(6):305-11. https://doi.org/10.1097/00000441-199506000-00001

15. Kambara H, Phillips J. Long-term evaluation of early repolarization syndrome (normal variant RS-T segment elevation). Am J Cardiol. 1976;38(2):157-6. https://doi.org/10.1016/0002-9149(76)90142-9

16. Nam GB, Kim YH, Antzelevitch C. Augmentation of J waves and electrical storms in patients with early repolarization. New EnglJ Med. 2008;358(19):2078-9. https://doi.org/10.1056\%2FNEJMc0708182

17. Cappato R, Furlanello F, Giovinazzo V, Infusino T, Lupo P, Pittalis $\mathrm{M}$, et al. J wave, QRS slurring, and ST elevation in athletes with cardiac arrest in the absence of heart disease: marker of risk or innocent bystander? Circ Arrhythm Electrophysiol 2010;3(4):30511. https://doi.org/10.1161/CIRCEP.110.945824

18. Miyazaki S, Shah AJ, Haïssaguerre M. Early repolarization syndrome - a new electrical disorder associated with sudden cardiac death. Jpn Circ J. 2010;74(10):2039-44. https://doi.org/10.1253/circj.CJ-10-0753

19. Adhikarla C, Boga M, Wood AD, Froelicher VF. Natural history of the electrocardiographic pattern of early repolarization in ambulatory patients. Am J Cardiol. 2011;108(12):1831-5. https://doi.org/10.1016/j.amjcard.2011.07.055

20. Siebermair J, Sinner MF, Beckmann BM, Laubender RP, Martens E, Sattler S, et al. Early repolarization pattern is the strongest predictor of arrhythmia recurrence in patients with idiopathic ventricular fibrillation: results from a single centre long-term follow-up over 20 years. Europace. 2016;18:718-25. https://doi.org/10.1093/europace/euv301

21. Sinner MF, Porthan K, Noseworthy PA, Havulinna AS, Tikkanen $J T$, Müller-Nurasyid M, et al. A meta-analysis of genomewide association studies of the electrocardiographic early repolarization pattern. Heart Rhythm. 2012;9(10):1627-34. https://doi.org/10.1016/j.hrthm.2012.06.008

22. Tikkanen JT, Wichmann V, Junttila MJ, Rainio M, Hookana E, Lappi O-P, et al. Association of early repolarization and sudden cardiac death during an acute coronary event. Circ Arrhythm Electrophysiol. 2012;5(4):714-8. https://doi.org/10.1161/CIRCEP.112.970863

23. Junttila MJ, Tikkanen JT, Kenttä T, Anttonen O, Aro AL, Porthan K, et al. Early repolarization as a predictor of arrhythmic and nonarrhythmic cardiac events in middle-aged subjects. Heart Rhythm. 2014;11(10):1701-6. https://doi.org/10.1016/j.hrthm.2014.05.024

24. Cheng YJ, Lin XX, Ji CC, Chen XM, Liu LJ, Tang K, et al. Role of early repolarization pattern in increasing risk of death. J Am Heart Assoc. 2016;5(9):1-10. https://doi.org/10.1161/JA 